\title{
Value Chain Creation in Business Analytics
}

\author{
Dong Kyoon Yoo \\ dyoo@vsu.edu \\ Virginia State University
}

\begin{abstract}
Firms are awash in big data and analytical technology as part of deriving values in the turbulent environment. The literature has somewhat reached a consensus that investments in technology only may not reap benefits from business analytics (BA). The main purpose of $B A$ is not about how to install technical capabilities, but about how to make a process whereby a firm builds a value chain converting data into insights, leading to quality decisions. Drawing upon the theory of the information value chain, this study develops a BA value chain model and tests it with 268 data scientists. Results show that organizational resilience, absorptive capacity, and analytical IT capabilities are critical antecedents to analytical decision-making quality which in turn influences $B A$ net benefits. Particularly, results illustrate that organizational resilience is a more significant variable impacting analytical decision-making quality than the influence of people and technology. Theoretical and practical implications are also discussed.
\end{abstract}

\section{Introduction}

Firms have encountered intense competition followed by constant demand for innovation and timeto-market pressures for survival and prosperity [30]. To thrive in such uncertain environments, business analytics (BA) has emerged with the premise that datadriven decision-making will lead firms to enhanced firm performance in the turbulent environment [34]. As such, organizations are investing more resources into BA as part of managing big data, turning into appropriate information, and leading to knowledge for effective decisions and actions. In doing so, there is somewhat a consensus that investments alone in information technology (IT) cannot generate expected benefits, although some technical areas such as data mining need to grow as opposed to big improvements in storage and processing [15].

The fundamental concern for BA is not about how to build technical capabilities but about how to make

\author{
James Jungbae Roh \\ roh@rowan.edu \\ Rowan University
}

best use of it in combination with quality decisions and improved performance [25]. The literature has reported that BA can be successful when it is supported by data quality [16, 17], IT capabilities [10, 29], organizations [10, 15], and skills and human capital [15,34], all of which are in need of coming into harmony for desired outcomes.

Given that extracting intelligence from big data underlies intertwined interactions among data, technology, organization, and people, the theory of the information value chain explains their exchanges, being depicted as "the cycle of converting data to information to knowledge to decisions to actions" [1]. The value chain compasses people, processes and technology [9], and the components are influenced by contextual factors such as organizational culture and IT governance [1]. Drawing upon the theory and the literature review of essential components of BA success, this study proposes a research model for value chain creation in BA and investigates the role of organizational resilience, analytical IT capabilities, absorptive capacity, and their impacts on BA outcomes such as analytical decision-making quality and BA net benefits. BA's desired outcomes are to achieve the congruence among organizational structure, IT, and human agency, but few studies have theoretically and empirically examined their interactions. While IT capabilities certainly perform a pivotal role in BA, attention should be also given to organizational background and employees' capabilities to use underlying resources to improve BA outcomes. This study will shed light on illustrating value chain creation in BA.

\section{Organizational resilience and value chain creation in BA}

A firm's resilient ability, translating adversity into opportunities, is an essential aspect of sustainability when faced disruptions on multiple fronts $[4,28,36]$. The original concept of resilience stems from physics where it is viewed as a physical ability to bounce back from a shock and to recover its original shape [32]. Researchers comprehend organizational resilience as a capability that responds to unfamiliar, challenging 
situations, develops appropriate responses, and further transforms disruptive surprises into opportunities for growth and sustainability [4, 28, 37]. It is somewhat surprising that the IS community has not thoroughly investigated its embodiment and influence on firm effectiveness despite the nature of rapid changes in the IT environment.

\subsection{Dimensions of organizational resilience}

Just as there exists various definitions of organizational resilience, the construct's dimensions have been presented in multiple ways. For instance, a study reports that organizational resilience consists of cognitive, behavioral, and contextual dimensions [22]. Forward-looking leadership, open organizational culture, strategic planning, and innovation are measured as dimensions of organizational resilience [26]. Another study finds that organizational resilience consists of capacities of reconfiguration, sensing, and seizing [36]. Differing dimensions of organizational resilience have been employed based upon each study's context. This study identifies vision salience, response capability, innovativeness, and resource access as critical dimensions of organizational resilience in the BA context.

Vision salience: A firm's vision is a practical guide for setting goals, making important decisions, and keeping the organization together for the mental picture for the future. A vision is defined as a vivid, idealized portrait of what the organization aspires to one day achieve [7]. Also, vision salience indicates the extent to which an organization is clearly aware of a shared sense of the firm's purpose and ultimate goals. Vision serves as the guiding perspective as a driving force to generate cohesion, and salient vision expands organizations to anticipate and counter opportunities and threats in the environment. Since vision amplifies a firm's ability to respond to opportunities or pressures for changes, it becomes particularly important during times of turbulence and transition. Salient vision encourages organizational members to form sensemaking and find meanings rather than becoming rigid and dysfunctional in the occurrence of disruptions [22].

Response capability: Turbulence may present emergent, unprecedented problems to the organization, and changing situations agitate a firm's operations. What's worse is that the problems are often unstructured and open-ended [2]. In such a disruptive circumstance, a firm's capability to respond is essential. Response capability is defined as the firm's ability to swiftly resolve issues and meaningfully solve problems [36, 41]. Disruptions demand immediate attention to the problems, and effective responses and solutions are certainly a prerequisite for a firm's survival and prosperity [14]. The capability to respond surmounts challenges and renews their competitive advantages by immediately assessing problems, effectively organizing resources, and rapidly providing solutions. Resilient organizations equipped with response capabilities can embark on rising uncertainties adequately and appropriately.

Innovativeness: An essential hallmark of organizational resilience is innovativeness [22, 26]. Disruptions often accompany daunting challenges to firms and make their extant competitive advantages obsolete. Firms can fall behind on account of the cliché and groupthink stemming from the previous accomplishments and the settlement to the status quo. Consequently, stagnant firms fail to seize the opportunity for changes in the market. Striving for forward-thinking and ground-breaking ways for renewals, resilient firms refuse to yield to abrupt plight and engender unconventional approaches to combating threats effectively. In an innovativenessencouraging atmosphere, organizational members feel motivated to make suggestions for new opportunities and take risks even if their endeavors may turn out to be failure. Such firms are constantly on the search for novel processes, technologies, and methods to arise from the adversity [36].

Resource access: Resource access has been well known in the literature as one of the critical aspects of organizational effectiveness $[5,43]$. Exuberant organizations hold a system conducive to locating and obtaining various resources including financial, human, and technical support. The literature has consistently recognized that a basis for a firm's competitive advantage lies in the allocation or configuration of tangible, intangible resources in a firm [5]. When a firm makes available a well-aligned access to resources, the execution of strategy and market responsiveness can flow to the needy place in a timely manner. In addition, the efficient mobility of resources enhances a firm's ability to cope with problems on the rise.

\section{Analytical IT capabilities and value chain creation in BA}

As IT plays a pivotal role in enabling data-driven processes and quality decision making [1], big dataspecific technology has enormously advanced in the past years [16]. BA toolsets such as ad hoc queries, dashboard, data mining, predictive analytics, and visualizations are of great use in analytics, and many vendors such as SAP, SAS, and IBM have invested their resources for technical improvements. BA use is 
the monumental driver of value creation in BA [34], and the academic community has acknowledged that system quality has long been regarded as an important part of IS success [13]. Big data are no value without a right tool, and big data's rise have amplified the importance of IT [1].

As part of IS success, system quality has received attention, and some dimensions have general applicability, while the relative importance of each dimension is dependent upon a specific setting [42]. In the context of BA, this study takes reliability, flexibility, accessibility, and integration as antecedents to analytical IT capabilities. Reliability refers to "the dependability of system operation" [42]. Flexibility refers to "the way the system adapts to changing demands of the user" [42]. Accessibility is described as the ease with which data can be accessed or extracted from the system [42]. The literature also defines integration as "the way the system allows data to be integrated from various sources [42]. Based upon the literature review, we present the following hypotheses in the context of BA.

\section{Hla: Reliability is positively related to analytical IT capability.}

H1b: Flexibility is positively related to analytical IT capability.

H1c: Accessibility is positively related to analytical IT capability.

H1d: Integration is positively related to analytical IT capability.

\section{Absorptive capacity and value chain creation in BA}

It is not surprising that studies on BA began with technical aspects because IT capabilities play a critical role in combining big data from different databases and analyze them to glean meaningful information. A study reports that IT capabilities have become standardized and homogenous and that technology itself may not bring competitive advantages over competitors [8]. That is, other capabilities, which is not easy to imitate right away, should be bundled with technology to provide firms with sustainable competitive advantages [8, 16]. The extant study supports that big data investments have failed because firms did not have a proper mechanism to read and react to intelligence gained from data [16]. In other words, equipping people with the capability to make use of data and take advantage of analytics is essential for the successful implementation of BA [31]. In this regard, the theory of absorptive capacity should be included in the value chain creation in BA as the construct is associated with the firm's ability to recognize value and apply it for commercial use.

Absorptive capacity is depicted as “a firm's ability to identify, assimilate, transform, and apply valuable external knowledge" [30]. It is related to organizational learning and critical to business success. Absorptive capacity is particularly important to enhance the understanding of accessing, adjusting, and advancing the influence of BA. Firms are under constant pressure to leverage their resources due to a high level of uncertainty and competition in the market. BA aims to correctly identify market situations, to transform its situations to opportunities, and sustain long-term competitive advantage. Investments in IT alone are often insufficient to generate lasting value [30], and the combination of BA technology and absorptive capacity will create a synergy effect.

The literature has examined three different conceptualizations of absorptive capacity: asset, substantive capability, or dynamic capability [30]. Asset is prior related knowledge, but this way of conceptualizing absorptive capacity is not recommended [30]. "Dynamic capability is distinguished from substantive capability in that dynamic capability refers to the ability to change or reconfigure existing substantive capabilities" [30, p. 628]. This study follows dynamic capabilities for absorptive capacity in the BA context.

\subsection{Organizational resilience and absorptive capacity in the BA value chain creation}

A firm's absorptive capacity inherently resides in mental models of organizational members, bring information and knowledge to situations, apply them for performance enhancement $[11,30]$. Studies report that a firm's structure and processes generally facilitate its absorptive capacity, and two organizational capabilities (i.e., coordination capabilities and socialization capabilities) are particularly crucial in examining the relationship between organizational resilience and absorptive capacity. Coordination capabilities indicate a firm's ability to manage the dependencies among its various activities [30], and socialization capabilities illustrate a firm's ability to produce shared mental models and collective interpretations of the reality [39, 30]. Dimensions of resilience (i.e., vision salience, response capability, innovativeness, and resource access) are related to the interplay of coordination and socialization among organizational members. In other 
words, resilience serves as a governance mechanism by enhancing cooperation, collaboration, and communication in the organization and further developing a collective mental model. It will help generate a high level of shared values, a common language, and well-established norms [30]. As organizational resilience will help improve absorptive capacity in a firm, we test the following hypothesis.

H2: Organizational resilience has a positive impact on absorptive capacity in the business analytics context.

\subsection{Analytical IT capability and absorptive capacity}

Analytical IT capabilities are certainly critical in utilizing big data and deriving meaningful information from structured, unstructured data. Spontaneously, studies have shown that business value chain can be fostered with the synergic interaction between IT capabilities and absorptive capacity [40, 30]. An organization's absorptive capacity will be enhanced when IT supplies significant enhancement with regard to computation, communication, and content. Quality data are useful, but discovering hidden patterns will enable the organization to have business insights and understand processes and outcomes. Research consistently shows that modern IT plays a critical role in the development and maintenance of absorptive capacity [30, 18]. Thus, we present the following hypothesis:

H3: Analytical IT capabilities have a positive impact on absorptive capacity in the business analytics context.

\section{BA analytical outcomes and value chain creation}

Both academicians and practitioners predict that a major contribution to firm performance will result from BA [34]. For elaborating on the impact on BA on firm performance, research has investigated outcomes such as supply chain performance [38], use of information in business processes [29], business intelligence success [17], big data analytics use and asset productivity [10], market and operational performance [16], and organizational benefits from analytics use from the perspective of senior management [34]. Analytical decision-making quality and business analytics net benefits are particularly chosen in this study as analytical outcomes in the BA value chain creation model because they essentially explain why organizations are of great interest in BA. Data-centric decision support is instrumental in organization's processes [21], and firms have tried to improve more evidence-based decision-making, given that the success of BA is a proper interaction between people and technology. Net benefit is an ultimate dependent variable that a firm wants to realize with the use of any type of technology eventually in their value creation [33]. Value chain creation in BA is based upon enhanced data-driven quality decision making and thus improved organizational performance.

\subsection{Analytical decision-making quality and value chain creation in $\mathbf{B A}$}

How an organization results in a better, evidencebased decision making is a long-standing research question. It is apparent that good decisions enhance firm value while poor ones will waste an organization's resources with ineffective capital investments, inefficient operations, and poor strategies. Not only do quality decisions include right answers in fast-moving decision environments, but it engages critical parties in the decision processes to attain better, smarter alignment and commitment to action [35].

Effective decision-making processes can be closely related to laying a foundation for a firm's focus and transforming their resources into realization. Vision salience plays a critical role in finding meanings of the impending challenges, helps the firm to regroup themselves, and make quality implementations. Visionary leaders and members inspired by the vision interpret the predicative circumstances in line with their strategic prospective and make decisions congruent to their goals [7, 20]. The quandary in a difficult situation may persist for a while, but it is digested in the context of the firm's vision, and such sense-making drives firms to reposition and reconfigure themselves to confront the challenges. Response capability with feasible solutions is another component that enables the organization to make quality decisions. Creative problem-solving capability is known as leading to innovative, excellent decision-making [2, 3, 14]. Approaching problems outside the traditional framework leads an organization to coalesce innovative ideas and reach landmark decisions. In addition, the pursuit of innovativeness in resilient firms often guides them to bold attempts to try out ideas in various forms and makes course-changing decisions [20]. Resource allocation is essential in enhancing the quality of the decision-making [12]. A firm endeavoring to find solutions for the problem needs support for not only financial resources but also 
technological, interorganizational resources to resolve imminent issues. Access to resources signifies how an organization approaches a matter and how much emphasis it places on the issue at hand. Thus, we present the following hypothesis.

H4: Organizational resilience has a positive impact on analytical decision-making quality.

Absorptive capacity is instrumental in increasing analytical decision-making quality. Knowledge transformed and applied through absorptive capacity offers a firm a clearer picture of the market landscape and the circumstance that the firm finds itself in. Valuable knowledge acquired by the organization assists the reallocation and restructuring of resources and expands stakeholders' understanding on various issues at hand. Disseminated knowledge empowers involved parties to make sense of market situations and put their capacity into practices. As such, absorptive capacity is helpful in clearing uncertainty, misperceptions, and confusions. It also opens the bases for the transparency, reprioritization, and even termination of decision-making by proffering the constant inflows of valuable knowledge to the firm [20]. Thus, we present the following hypothesis.

\section{H5: Absorptive capacity has a positive impact on analytical decision-making quality.}

Effective BA is to improve data processing for the purpose of delivering data-centric decision support which will lead to quality decision-making. Firms face uncertain circumstances where the demand of analytics frequently changes and data needed are not obvious at the outset [21]. These situations require firms to be equipped with a high level of flexibility and adaptability in terms of analytical capabilities. Dashboards, ad-hoc queries, and data visualizations to analyze routine, non-routine data enable organizational members to better understand rapidly changing market situations and support more datadriven decisions. The massive reduction to access big data can allow decision makers to search for information in a timely manner, and proper analytical tools to investigate their impact help organizational members have insights to the situation and problem solutions, which will lead to effective decisions [34]. Accordingly, this study tests the following hypothesis.

H6: Analytical IT capability has a positive impact on analytical decision-making quality.

\subsection{Net benefits and value chain creation in BA}

The ultimate dependent variable in the BA value chain creation model is net benefits which are an overall measure of the firm's perception of benefits gleaned from the use of BA. The literature shows that net benefits are considered as one of the most critical success measures of IT acceptance and use, and such benefits include cost savings, expanded markets, incremental additional sales, reduced search costs, or time savings [13]. As studies use organizational benefits and business value interchangeably [33, 34], this study investigates value chain creation in BA and sets net benefits as an ultimate dependent variable.

Despite the fact that data are often compared to new oil of changes, firms have yet been struggling to see promises being fulfilled. One of the crucial reasons can be traced back to decision-making quality. The plethora of data and abundant analytics tools do not necessarily mean that firms take information unfolded and decipher it in a way that is formative for their business. Constant, hefty investments in BA will be appreciated when firms experience a certain form of values. Such benefits fall on firms when a high quality of analytical decision-making takes place. In the face of tough competitions, high quality decision making relieves stakeholders from uneasiness and sends assurance to parties involved in the decision-making process. When better decisions are made with the help from analytics, organizational members sense the value of analytics and become satisfied with the endeavors to integrate BA into the fabric of the firm [19]. The benefits of BA clearly emerge in a tangible manner when it is actively and proactively used across the corporate landscape and even take central roles in decision making and implementations. Thus, we present the following hypothesis.

H7: Analytical decision-making quality has a positive impact on business analytics net benefits.

\section{Research methods}

The research framework was examined using a survey methodology, and its measurement and structural models were tested by SmartPLS 2.0. Instruments for vision salience were drawn from Oswald et al. [27]. Instruments for response capability and resource access were taken from Mallak [24]. Innovativeness' items were adapted from Bock et al. [6]. Items for absorptive capacity were adopted from Iyengar et al. [18]. Analytical IT capability was drawn from Popovič et al. [29]. Antecedents to analytical IT capability (i.e., reliability, flexibility, accessibility, and integration) were adopted from Wixom and Todd [42]. Survey items for analytical decision-making 
quality were taken from Kowalczyk and Buxmann [21]. BA net benefit was taken from DeLone and McLean [13]. All survey instruments were asked to mark on a seven-point Likert scale where 1 was "Strongly Disagree" and 7 was "Strongly Agree." All instruments used in this study were adapted to this study's context. Decision types, competition, and a level of industry innovation were controlled in this study to better examine the impact of value chain creation in BA.

To test the research model, the developed survey was distributed to the data scientists in various industries through a professional data collection company. The data collection proceeded with two phases. A pilot study was first implemented with a little over 50 responses from data scientists. After checking the convergent and discriminant validity, a few items were changed and fine-tuned, and then the large-scale data collection launched. A total of 1,022 were invited to answer the survey, and 268 data scientists completed them, resulting in $26.2 \%$ response rate. Responses consist of retail (5\%), finance/banking $(9 \%)$, healthcare $(6 \%)$, manufacturing $(12 \%)$, data analytics (12\%), IT $(20 \%)$, software/telecommunication (8\%), education (4\%), and government (4\%) sectors. The size of the firm was 100-249 (16\%), 250-499 (12\%), 500-999 (24\%), 1,000-2,499 (16\%), and 2,500 and over (22\%). Average annual sales from firms were: less than 10 million (14\%), 10-49.9 million (21\%), 50-99.9 million (15\%), 100-499.9 million (19\%), 500-1 billion (13\%), and over 1 billion (9\%). Response/non-response bias was examined by comparing earlier responses with later ones. The two groups were compared on annual sales and the number of employees with a Chi-squire test. No significant differences were found.

\subsection{Measurement model}

Confirmatory factor analysis was examined with SmartPLS 2.0 to test convergent and discriminant validity. Convergent validity was tested by item loadings, composite reliabilities, and average variance extracted (AVE). All item loadings, shown in Table 1, were greater than 0.700 . The lowest composite reliability was 0.867 which was higher than the 0.700 threshold. AVE in all constructs were greater than .500. Discriminant validity was examined by the square root of AVE for the associate construct which needs to be higher than all respective correlations. As shown in Table 2, data used in this study had no concern for discriminant validity.

A common method bias could be problematic in self-reported data, and this study followed the PLS model developed by Liang et al. [23]. The average variance explained by substantive indicators and the method were .694 and .005 , and thus the common method bias deemed not to be an issue.

Table 1. Item loadings of confirmatory factor analysis

\begin{tabular}{|c|c|c|c|c|c|c|}
\hline & AC & ACC & DQ & CAP & FLE & INN \\
\hline AC1 & $\mathbf{0 . 7 3 0}$ & 0.465 & 0.508 & 0.503 & 0.555 & 0.554 \\
\hline AC2 & $\mathbf{0 . 7 8 5}$ & 0.500 & 0.550 & 0.527 & 0.544 & 0.597 \\
\hline C3 & $\mathbf{0 . 7 7 2}$ & 0.451 & 0.539 & 0.540 & 0.516 & 0.588 \\
\hline AC4 & $\mathbf{0 . 7 7 7}$ & 0.508 & 0.548 & 0.563 & 0.598 & 0.550 \\
\hline AC5 & $\mathbf{0 . 8 0 5}$ & 0.449 & 0.620 & 0.593 & 0.602 & 0.557 \\
\hline AC6 & $\mathbf{0 . 7 9 8}$ & 0.447 & 0.590 & 0.565 & 0.582 & 0.572 \\
\hline AC7 & $\mathbf{0 . 7 8 7}$ & 0.426 & 0.597 & 0.564 & 0.574 & 0.546 \\
\hline AC8 & $\mathbf{0 . 7 7 0}$ & 0.523 & 0.625 & 0.570 & 0.541 & 0.581 \\
\hline AC9 & $\mathbf{0 . 7 8 5}$ & 0.515 & 0.580 & 0.597 & 0.584 & 0.559 \\
\hline ACC1 & 0.580 & $\mathbf{0 . 9 0 7}$ & 0.575 & 0.529 & 0.586 & 0.565 \\
\hline ACC2 & 0.550 & $\mathbf{0 . 9 4 1}$ & 0.577 & 0.545 & 0.604 & 0.585 \\
\hline ACC3 & 0.562 & $\mathbf{0 . 9 2 3}$ & 0.559 & 0.582 & 0.606 & 0.601 \\
\hline DQ1 & 0.683 & 0.559 & $\mathbf{0 . 8 9 2}$ & 0.569 & 0.619 & 0.644 \\
\hline DQ2 & 0.633 & 0.516 & $\mathbf{0 . 8 8 8}$ & 0.524 & 0.573 & 0.569 \\
\hline DQ3 & 0.649 & 0.570 & $\mathbf{0 . 8 8 8}$ & 0.596 & 0.592 & 0.591 \\
\hline CAP1 & 0.542 & 0.431 & 0.478 & $\mathbf{0 . 7 7 4}$ & 0.493 & 0.420 \\
\hline CAP2 & 0.519 & 0.477 & 0.466 & $\mathbf{0 . 7 6 1}$ & 0.493 & 0.503 \\
\hline CAP3 & 0.471 & 0.472 & 0.449 & $\mathbf{0 . 7 0 4}$ & 0.442 & 0.503 \\
\hline CAP4 & 0.599 & 0.478 & 0.488 & $\mathbf{0 . 8 2 4}$ & 0.615 & 0.503 \\
\hline CAP5 & 0.644 & 0.481 & 0.577 & $\mathbf{0 . 8 2 7}$ & 0.611 & 0.489 \\
\hline FLE1 & 0.627 & 0.532 & 0.608 & 0.578 & $\mathbf{0 . 8 7 9}$ & 0.504 \\
\hline FLE2 & 0.674 & 0.525 & 0.607 & 0.615 & $\mathbf{0 . 8 9 4}$ & 0.579 \\
\hline FLE3 & 0.614 & 0.649 & 0.551 & 0.616 & $\mathbf{0 . 8 6 3}$ & 0.575 \\
\hline INN1 & 0.630 & 0.527 & 0.594 & 0.492 & 0.550 & $\mathbf{0 . 8 3 8}$ \\
\hline INN2 & 0.539 & 0.531 & 0.504 & 0.505 & 0.491 & $\mathbf{0 . 7 9 0}$ \\
\hline INN3 & 0.605 & 0.507 & 0.580 & 0.511 & 0.513 & $\mathbf{0 . 8 5 2}$ \\
\hline INN4 & 0.662 & 0.559 & 0.589 & 0.566 & 0.558 & $\mathbf{0 . 8 7 3}$ \\
\hline & & & & & & \\
\hline
\end{tabular}

\begin{tabular}{|c|c|c|c|c|c|c|}
\hline & INT & NB & RA & RC & REL & VS \\
\hline INT1 & $\mathbf{0 . 8 8 8}$ & 0.490 & 0.139 & 0.510 & 0.593 & 0.439 \\
\hline INT2 & $\mathbf{0 . 8 6 8}$ & 0.509 & 0.163 & 0.485 & 0.572 & 0.474 \\
\hline INT3 & $\mathbf{0 . 8 2 5}$ & 0.490 & 0.137 & 0.473 & 0.543 & 0.398 \\
\hline NB1 & 0.415 & $\mathbf{0 . 7 6 9}$ & 0.250 & 0.464 & 0.485 & 0.459 \\
\hline NB2 & 0.449 & $\mathbf{0 . 7 5 9}$ & 0.205 & 0.379 & 0.495 & 0.416 \\
\hline NB3 & 0.438 & $\mathbf{0 . 7 9 0}$ & 0.225 & 0.394 & 0.497 & 0.406 \\
\hline NB4 & 0.462 & $\mathbf{0 . 8 1 0}$ & 0.146 & 0.481 & 0.453 & 0.538 \\
\hline NB5 & 0.481 & $\mathbf{0 . 7 5 5}$ & 0.137 & 0.546 & 0.541 & 0.515 \\
\hline RA1 & 0.179 & 0.229 & $\mathbf{0 . 8 7 2}$ & 0.187 & 0.206 & 0.180 \\
\hline RA2 & 0.113 & 0.189 & $\mathbf{0 . 7 9 1}$ & 0.079 & 0.147 & 0.135 \\
\hline RA3 & 0.100 & 0.175 & $\mathbf{0 . 7 4 3}$ & 0.056 & 0.108 & 0.084 \\
\hline RA4 & 0.131 & 0.185 & $\mathbf{0 . 7 3 8}$ & 0.097 & 0.136 & 0.084 \\
\hline RC1 & 0.451 & 0.442 & 0.110 & $\mathbf{0 . 7 6 6}$ & 0.480 & 0.480 \\
\hline RC2 & 0.494 & 0.525 & 0.163 & $\mathbf{0 . 8 5 7}$ & 0.514 & 0.477 \\
\hline RC3 & 0.440 & 0.422 & 0.104 & $\mathbf{0 . 8 2 0}$ & 0.416 & 0.413 \\
\hline RC4 & 0.456 & 0.493 & 0.086 & $\mathbf{0 . 7 9 3}$ & 0.496 & 0.511 \\
\hline REL1 & 0.643 & 0.578 & 0.211 & 0.539 & $\mathbf{0 . 9 1 2}$ & 0.545 \\
\hline REL2 & 0.565 & 0.557 & 0.163 & 0.517 & $\mathbf{0 . 9 0 2}$ & 0.540 \\
\hline REL3 & 0.589 & 0.584 & 0.165 & 0.543 & $\mathbf{0 . 8 9 9}$ & 0.532 \\
\hline VS1 & 0.453 & 0.564 & 0.191 & 0.539 & 0.480 & $\mathbf{0 . 9 1 4}$ \\
\hline
\end{tabular}




\begin{tabular}{|l|l|l|l|l|l|l|}
\hline VS2 & 0.477 & 0.536 & 0.111 & 0.525 & 0.610 & $\mathbf{0 . 9 1 4}$ \\
\hline
\end{tabular}

Table 2. Descriptive statistics, correlations and average variance extracted

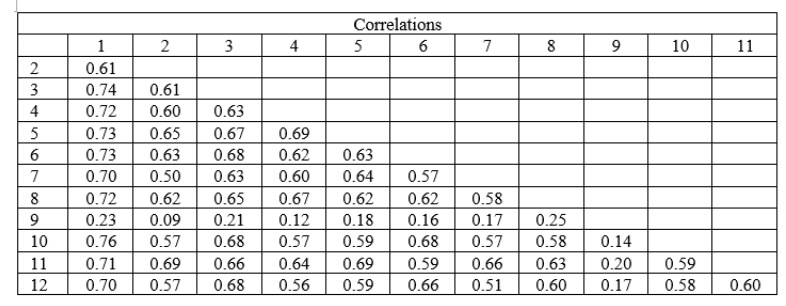

\begin{tabular}{|l|c|c|c|}
\hline & AVE & $\begin{array}{l}\text { Composite } \\
\text { Reliability }\end{array}$ & Cronbach's Alpha \\
\hline AC & 0.607 & 0.933 & 0.919 \\
\hline ACC & 0.853 & 0.946 & 0.914 \\
\hline DQ & 0.791 & 0.919 & 0.868 \\
\hline CAP & 0.607 & 0.885 & 0.838 \\
\hline FLE & 0.772 & 0.910 & 0.852 \\
\hline INN & 0.704 & 0.905 & 0.859 \\
\hline INT & 0.740 & 0.895 & 0.824 \\
\hline NB & 0.604 & 0.884 & 0.836 \\
\hline RA & 0.621 & 0.867 & 0.813 \\
\hline RC & 0.656 & 0.884 & 0.825 \\
\hline REL & 0.818 & 0.931 & 0.889 \\
\hline VS & 0.836 & 0.911 & 0.804 \\
\hline
\end{tabular}

\subsection{Structural model}

The BA value chain creation model was examined by reviewing path coefficients and percentage of variance explained. With respect to antecedents to analytical IT capabilities, flexibility $(\beta=.344, p<$ $0.01)$, accessibility $(\beta=.175, \mathrm{p}<0.05)$, and integration $(\beta=.195, \mathrm{p}<0.05)$, had a positive, significance influence, supporting H1b, H1c, and H1d. Reliability showed a positive influence on analytical IT capability $(\beta=.155, p<0.10)$, but its significance is weak. It is surprising that flexibility emerges as the strongest factor for analytical IT capability.

As hypothesized in $\mathrm{H} 2$ and $\mathrm{H} 3$, organizational resilience $(\beta=.645, \mathrm{p}<0.01)$ and analytical IT capability $(\beta=.291, \mathrm{p}<0.01)$ turned out exerting significant influences on absorptive capacity. It is noteworthy to mention the conspicuous impact of organizational resilience on absorptive capacity. The capacity to absorb information and translate it into actionable knowledge does not solely depend on analytical capability but on cultivating knowledgereceptive and change-adaptive human components.

Subsequently, the research model examined the impact that organizational resilience, absorptive capacity, and IT capability bring to analytical decision-making quality. The structural model revealed their strong effects, which were organizational resilience $(\beta=.491, \mathrm{p}<0.01)$, absorptive capacity $(\beta=.207, \mathrm{p}<0.05)$, and analytical IT capability $(\beta=.158, \mathrm{p}<0.05)$. The three constructs all increased analytical decision-making quality, and notably organizational resilience exhibited the strongest effect. As such, the results support H4, H5, and $\mathrm{H} 6$.

Lastly, analytical decision-making quality enhanced BA net benefit $(\beta=.641, \mathrm{p}<0.01)$ considerably and thereby confirmed $\mathrm{H} 7$. In fact, the impact was the greatest, in terms of the size of the coefficient and shows the criticality of decisionmaking quality in boosting BA net benefits. As for control variables, decision type, competition, and industry innovation level all were insignificant other than the link between decision type and analytical decision-making quality.

The variance in analytical IT capability is $55.7 \%$. In the case of the variances of absorptive capacity and analytical decision-making quality, the figures of $74.7 \%$ and $64.4 \%$ were explained. In addition, the model explained $43.5 \%$ of the variance in business analytics net benefit.

\section{Discussion}

A great interest in BA along with its variants such as big data analytics and business intelligence \& analytics has been raised [1,34]. Not only does BA involve streamlined databases and user-friendly, versatile analytical tools, but the dynamic integration with knowledge workers for turning data into decision is essential. This study develops a research model exploring BA value chain creation with business factors for the successful deployment of BA in the organization.

\subsection{Implication for research}

The first contribution lies in capturing the value creation process in BA through the research model. The theory of the information value chain describes that the aligned interaction among people, processes and technology will enhance a firm's value by converting data into information and further to knowledge and action [1, 9]. However, the dynamics of a value chain on BA has relatively received little attention [1], and this study makes a contribution to elaborating on the value chain creation model in BA. Research has illustrated that the true value of investments in IT can be realized with managerial skills, IT infrastructure and a firm's intellectual capital (Gupta and George 2016). The value chain creation in BA can be disappointing without the complementation of supporting human processes in incorporating 
valuable knowledge and insights into decisionmaking. This study presents a research framework that facilitates value chain creation in BA with a holistic approach of organizational resilience, IT capabilities, absorptive capacity, and decision outcomes. This model helps the community of analytics realize tangible, intangible business values from BA and investigates how they interact in organizations. Overall, results of the study confirm that our variables are significant in the context of BA. The second theoretical implication comes from the illumination of the role of absorptive capacity in the BA context. This research identifies absorptive capacity as an important link between investments in BA and their outcomes. As previous studies have indicated $[15,16]$, IT alone is insufficient to materialize knowledge obtained via analytics, and BA has to be equipped with a process of appreciating findings and reflecting them in decisionmaking. The process is characterized as an ability to identify significant information, assimilate or transform it into a firm's knowledge bases, and apply it into innovative decisions and actions. Absorptive capacity has been treated as an important IS research stream [18, 30], but to our knowledge, a dearth of studies have delved into this important area in the context of BA. In line with the theory of the information value chain, absorptive capacity is the portion of people where the constituents of an organization actively engage in learning and applying knowledge into actions in a prompt manner. Our statistical results make a contribution to this theoretical link.

The third theoretical implication arises from the clarification of antecedents to analytical decisionmaking quality. This research posits, besides analytical IT capabilities, two other antecedents, namely, organizational resilience and absorptive capacity. The theoretical significance of absorptive capacity was explained above, and another important construct is organizational resilience. Surprisingly, organizational resilience has not been examined in the context of BA, given that analytics can play a significant role in the turbulent environment. This study contributes to the analytical literature by investing the nature, role, and impact of organizational resilience on BA outcomes. Both theoretical construction and empirical findings suggest that organizational resilience is a crucial driver for BA.

Finally, this research adds insights to the literature by clarifying critical outcomes of BA in the value chain model. Analytics without tangible goals may not find its role and position in an organization, and effective analytics demonstrates its significance in its results. The results can take forms of cost savings, expanded markets, incremental additional sales, reduction in search effort, or time savings. Also, the value of analytics should emerge palpable throughout the organization, and one of the powerful ways is to see the enhanced quality of decision-making and subsequent bottom line improvements. As part of information value chain creation, this research points to important outcomes of BA.

\subsection{Implication for practice}

BA is to leverage data and enable timely decisionmaking for firm performance while empowering organizational members in the fast-moving environment. The results of this study indicate that firms should be aware of the duality of technology. IT alone cannot serve the purpose of $\mathrm{BA}$, and the supporting dynamics has to be established to properly implement BA in an organization. Studies show that collecting hordes of data from a variety of sources is unlikely to be a competitive advantage, and a firm needs to create invisible dynamics such as the structure of an organization and resilient employees for the success of BA [16]. In other words, BA technology along with the alignment of people and an organization's structure will make a difference. Although firms recognize analytics as a necessity, it does not necessarily mean that they reap full benefits from it. Instead, the firm's ability to interpret data and combine them with their intuitions and initiatives are critical to maximizing the value of analytics.

The size of path coefficients shows the relative importance of constructs. While organizational resilience, absorptive capacity, and analytical IT capabilities are significant variables to affect analytical decision-making quality, organizational resilience has more impact on analytical decisionmaking quality than the others. Resilient firms have a tendency to make high-quality decisions in the presence of disruptions and crises. They may suffer difficult hardships but resurface from them stronger than before. More often than not, the core of such resilience can be found in the right decisions made during the crises.

As for analytical IT capabilities, the variable impacts the firm's ability to identify, assimilate and transform new patterns and interesting emergence in the market and then leads to analytical decisionmaking quality. Results also show that reliability, flexibility, accessibility, and integration are critical aspects of enhancing analytical IT capabilities. Firms with efficient BA technology exhibit an organizational members' proficiency and prowess with analytics. Such impacts create synergistic effects on the use of analytics and present the benefits to more contributors. 


\subsection{Limitations and suggestions for future research}

This study has some limitations which may open opportunities for future studies. This study has proposed and tested the BA value chain model, and applying and interpreting the model in a new context need modifications. The data collected from data scientists in this study measure their perception. Respondents may have a tendency to rate their perceptions in a positive way. Particularly, this study measured net benefits with cost savings, expanded markets, incremental additional sales, reduced search costs, or time saving [13]. Future studies may directly use financial/econometrics data such as ROI on firm performance. This study has used a single respondent to measure constructs at the organizational level. Future studies may attempt to use multiple respondents for better understanding the $\mathrm{BA}$ value chain model.

\section{Conclusion}

Firms should reconfigure their resources flexibly based upon changing market conditions. In particular, firms have turned the spotlight on BA that helps recognize the surrounding circumstances and strive to transform both opportunities and threats into moments for improvement, renewal, and innovation. This study develops value chain creation in BA by encompassing data, IT, organization, people and their influences on performance. This study uncovers the criticality of organizational resilience and absorptive capacity in enhancing the quality of decision-making in the context of BA investments and usage. Few studies have been undertaken for value chain creation in BA, and this study enlightens the BA community with theoretical implications and practical contributions.

\section{References}

[1] A. Abbasi, S. Sarker, and R.H. Chiang, "Big data research in information systems: Toward an inclusive research agenda", Journal of the Association for Information Systems, 17(2), 2016, pp. i - xxxii.

[2] N. Althuizen, and A. Reichel, "The Effects of IT-Enabled Cognitive Stimulation Tools on Creative Problem Solving: A Dual Pathway to Creativity", Journal of Management Information Systems, 33(1), 2016, pp. 11-44.

[3] N. Althuizen, and B. Wierenga, "Supporting creative problem solving with a case-based reasoning system", Journal of Management Information Systems, 31(1), 2014, pp. 309-340.

[4] S. Ambulkar, J. Blackhurst, and S. Grawe, "Firm's resilience to supply chain disruptions: Scale development and empirical examination", Journal of Operations Management, 33, 2015, pp. 111-122.

[5] S. Ayabakan, I.R. Bardhan, and Z. Zheng, "A Data Envelopment Analysis Approach to Estimate IT-Enabled Production Capability", MIS Quarterly, 41(1), 2017, pp. 189-205.

[6] G.-W. Bock, R.W. Zmud, Y.-G. Kim, and J.-N. Lee, "Behavioral intention formation in knowledge sharing: Examining the roles of extrinsic motivators, socialpsychological forces, and organizational climate", MIS Quarterly, 29(1), 2005, pp. 87-111.

[7] A.M. Carton, C. Murphy, and J.R. Clark, "A (blurry) vision of the future: How leader rhetoric about ultimate goals influences performance", Academy of Management Journal, 1015(1), 2015, pp. 10-36.

[8] H.-C. Chae, C.E. Koh, and V.R. Prybutok, "Information Technology Capability and Firm Performance: Contradictory Findings and Their Possible Causes", MIS Quarterly, 38(1), 2014, pp. 305-326.

[9] Chandler, N., B. Hostmann, N. Rayner, and G. Herschel, Gartner's Business Analytics Framework, Gartner, Connecticut, USA, 2011.

[10] D.Q. Chen, D.S. Preston, and M. Swink, "How the Use of Big Data Analytics Affects Value Creation in Supply Chain Management", Journal of Management Information Systems, 32(4), 2015, pp. 4-39.

[11] W.M. Cohen, and D.A. Levinthal, "Absorptive capacity: A new perspective on learning and innovation", Administrative Science Quarterly, 35, 1990, pp. 128-152.

[12] M. Cording, P. Christmann, and D.R. King, "Reducing causal ambiguity in acquisition integration: Intermediate goals as mediators of integration decisions and acquisition performance." Academy of Management Journal, 51(4), 2008, pp. 744-767.

[13] W.H. DeLone, and E.R. McLean, "The DeLone and McLean model of information systems success: a ten-year update", Journal of Management Information Systems, 19(4), 2003, pp. 9-30.

[14] K. Figl, and J. Recker, "Process innovation as creative problem solving: An experimental study of textual descriptions and diagrams", Information \& Management, 53(6), 2016, pp. 767-786.

[15] K. Gillon, S. Aral, C.-Y. Lin, S. Mithas, and M. Zozulia, "Business Analytics: Radical Shift or Incremental Change?", Communications of the Association for Information Systems, 34(1), 2014, pp. 287-296.

[16] M. Gupta, and J.F. George, "Toward the development of a big data analytics capability", Information \& Management, 53(8), 2016, pp. 1049-1064.

[17] Ö. Işık, M.C. Jones, and A. Sidorova, "Business intelligence success: The roles of BI capabilities and decision environments", Information \& Management, 50(1) 2013, pp. 13-23.

[18] K. Iyengar, J.R. Sweeney, and R. Montealegre, "Information technology use as a learning mechanism: the impact of IT use on knowledge transfer effectiveness, absorptive capacity, and franchisee performance", MIS Quarterly, 39(3), 2015, pp. 615-641.

[19] M. Janssen, H. van der Voort, and A. Wahyudi "Factors influencing big data decision-making quality", Journal of Business Research, 70, 2017, pp. 338-345. 
[20] A. Kock, and H. Gemünden, “Antecedents to DecisionMaking Quality and Agility in Innovation Portfolio Management", Journal of Product Innovation Management, 33(6), 2016, pp. 670-686.

[21] M. Kowalczyk, and P. Buxmann, "An ambidextrous perspective on business intelligence and analytics support in decision processes: Insights from a multiple case study", Decision Support Systems, 80, 2015, pp. 1-13.

[22] C.A. Lengnick-Hall, T.E. Beck, and M.L. LengnickHall, "Developing a capacity for organizational resilience through strategic human resource management", Human Resource Management Review, 21(3), 2011, pp. 243-255.

[23] H. Liang, N. Saraf, Q. Hu, and Y. Xue, “Assimilation of enterprise systems: The effect of institutional pressures and the mediating role of top management", MIS Quarterly, 31(1), 2007, pp. 59-87.

[24] L.A. Mallak, "Measuring resilience in health care provider organizations", Health Manpower Management, 24(4), 1998, pp. 148-152.

[25] Marr, B., Big Data: Using SMART big data, analytics and metrics to make better decisions and improve performance, John Wiley \& Sons, Hoboken, New Jersey, 2015.

[26] E. de Oliveira Teixeira, and W.B. Werther, "Resilience: Continuous renewal of competitive advantages", Business Horizons, 56(3), 2013, pp. 333-342.

[27] S.L. Oswald, K.W. Mossholder, and S.G. Harris, "Vision salience and strategic involvement: Implications for psychological attachment to organization and job", Strategic Management Journal 15(6), 1994, pp. 477-489.

[28] I. Park, R. Sharman, and H.R. Rao, "Disaster Experience and Hospital Information Systems: An Examination of Perceived Information Assurance, Risk, Resilience, and HIS Usefulness", MIS Quarterly, 39(2) 2015, pp. 317-344.

[29] A. Popovič, R. Hackney, P.S. Coelho, and J. Jaklič, "Towards business intelligence systems success: Effects of maturity and culture on analytical decision making", Decision Support Systems, 54, 1, 2012, pp. 729-739.

[30] N. Roberts, P.S. Galluch, M. Dinger, and V. Grover, "Absorptive Capacity and Information Systems Research: Review, Synthesis, and Directions for Future Research", MIS Quarterly, 36(2), 2012, pp. 625-648.

[31] J.W. Ross, C.M. Beath, and A. Quaadgras. "You may not need big data after all", Harvard Business Review, 91(12), 2013, pp. 90-98.

[32] J.W. Rudolph, and N.P. Repenning, "Disaster dynamics: Understanding the role of quantity in organizational collapse”, Administrative Science Quarterly, 47(1), 2002, pp. 1-30.

[33] P.B. Seddon, C. Calvert, and S. Yang, "A multi-project model of key factors affecting organizational benefits from enterprise systems", MIS Quarterly, 34(2), 2010, pp. 305328.

[34] P.B. Seddon, D. Constantinidis, T. Tamm, and H. Dod, "How does business analytics contribute to business value?" Information Systems Journal, 27(3), 2017, pp. 237-269.

[35] Spetzler, C., H. Winter, and J. Meyer, "Decision Quality: Value Creation from Better Business Decisions", John Wiley \& Sons, Hoboken, New Jersey, 2016.
[36] H.-C. Su, and K. Linderman, "An Empirical Investigation in Sustaining High-Quality Performance", Decision Sciences, 47(5), 2016, pp. 787-819.

[37] K.M. Sutcliffe, and T.J. Vogus, "Organizing for resilience", Positive Organizational Scholarship, 2003, pp. 94-110.

[38] P. Trkman, K. McCormack, M.P.V. De Oliveira, and M.B. Ladeira, "The impact of business analytics on supply chain performance", Decision Support Systems, 49(3), 2010, pp. 318-327.

[39] F.A. Van Den Bosch, H.W. Volberda, and M. De Boer, "Coevolution of firm absorptive capacity and knowledge environment: Organizational forms and combinative capabilities", Organization Science, 10(5), 1999, pp. 551568.

[40] M. Wade, and J. Hulland, "Review: The resource-based view and information systems research: Review, extension, and suggestions for future research", MIS Quarterly, 28(1), 2004, pp. 107-142.

[41] Weick, K.E., and K.M. Sutcliffe, Managing the unexpected: Resilient performance in an age of uncertainty (2nd ed.). Jossey-Bass, San Francisco, USA, 2007.

[42] B.H. Wixom, and P.A. Todd, "A theoretical integration of user satisfaction and technology acceptance", Information Systems Research, 16(1), 2005, pp. 85-102.

[43] S.P.-J. Wu, D.W. Straub, and T.-P. Liang, "How information technology governance mechanisms and strategic alignment influence organizational performance: Insights from a matched survey of business and IT managers", MIS Quarterly, 39(2), 2015, pp. 497-518. 